\title{
المؤشر الإنتاجي لأعمال الخرسانات المصبوية بالمكان في السودان
}

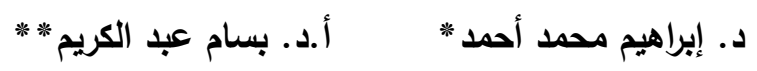

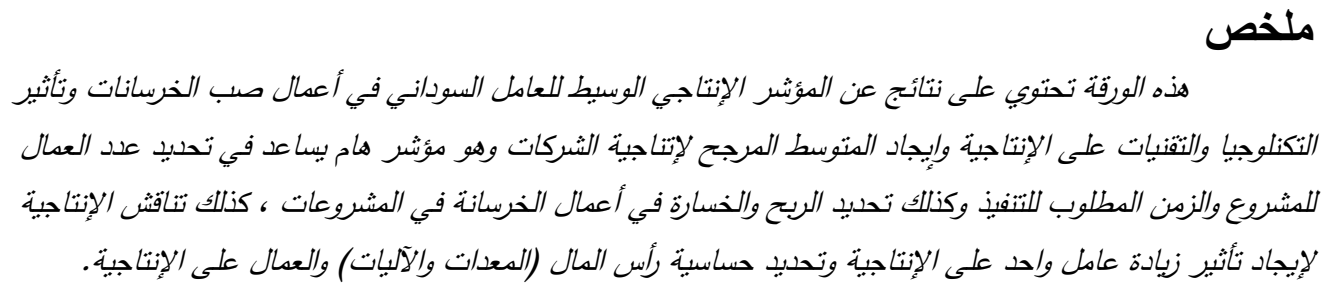

\begin{abstract}
This paper is oriented to the results of Productivity of Laborers in concrete construction companies in the Sudan. Also the effect of equipment and plants based on the average productivity of the construction companies. The factor is very important to specify the number of workers, time required for construction as well as the profit and loss. Lastly the effects of increase of the number of workers on the productivity and to specify the sensitivity of equipment, plants, and workers on the productivity.

Key words - Productivity - profit and loss.
\end{abstract}


تمتلئ أدبيات العلوم الإقتصادية والهندسية وبشكل خاص العلوم التطبيقية في مجملها بأفكار

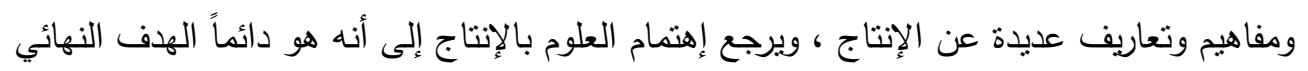

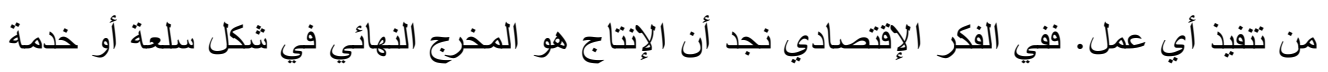

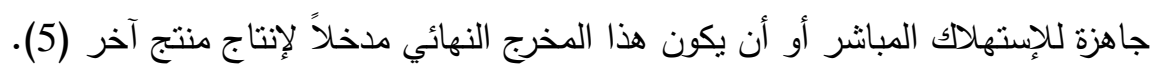

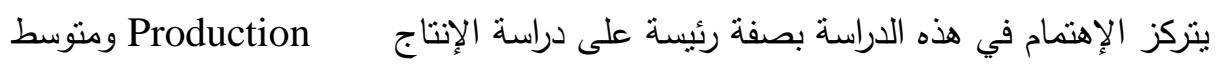

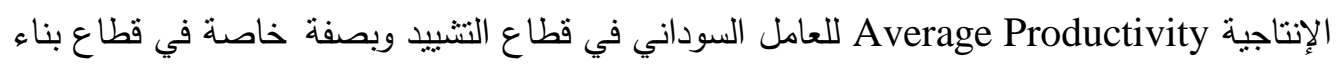
الهياكل الخرسانية وكذلك قياس الإنتاجية الحدية (Marginal Productivity) لعوامل الإنتاج الرئيسية كما هي معرفة في الفكر الإقتصادي وبصفة خاصة في دالة إنتاج كوب دوجلاس Cobb Douglas [3]Production Function والتكنلوجيا المستخدمة بالإضافة إلى العمال كعوامل إنتاج في قطاع التتبيد وذلك لأهمية قطاع التثبيد في إجمالي الناتج المحلي. 2.1 أنبع المنهج الوصفي التحليلي وجمعت البيانات الأولية من شركات المقاولات التي تعمل في مجال النتييد عن طريق الإسنتيان.

\section{1}

يتألف مجتمع الدراسة من شركات المقاولات التي تعمل في مجال التشييد (في الخرسانات).

$$
\begin{aligned}
& \text { 1. تم إختيار ولاية الخرطوم للأسباب الآتية: } \\
& \text { 2. تتمتع ولاية الخرطوم بأكبر كتلة سكانية من بين ولايات السودان. } \\
& \text { 3. تتمتع ولاية الخرطوم بنقل سياسي كبير . }
\end{aligned}
$$

4. تتمتع ولاية الخرطوم [1] بنقل إقتصادي كبير حيث تتمركز معظم الإستثمارات الوطنية الكبيرة في الإنشاءات في ولاية الخرطوم , كذللك تمركز أكثر من ثلثي الودائع المصرفية في السودان في ولاية الخرطوم ، وعليه فإن المؤنشرات المستخلصة من بيانات هذه الدراسة تمثل

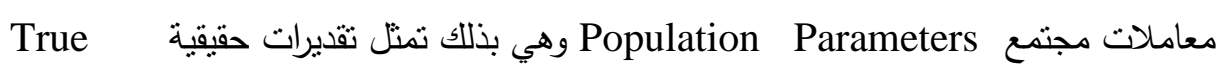
Estimates المستقبل. 
3.1 وحدة قياس عناصر المجتمع:

في هذه الدراسة يوجد عدد كبير من الشركات في ولاية الخرطوم تعمل في مجال أعمال

النتييد ولإختيار الثركة المعينة وفي ما يعرف بوحدة قياس عناصر المجتمع وضعنا الثروط

التالية: أ. شهادة التسجيل لدى مسجل الثركات حسب قانون الثركات لعام 1925م. ب. أن تكون الثركة منضمة لإتحاد المقاولين. ج.أن تكون الثركة الهندسية عاملة خلال السنوات الخمس الأخيرة من ناريخ الدراسة. د. تقوم بدفع الضرائب والإلتزامات المالية الأخرى عليها لوزارة المالية بإنتظام.

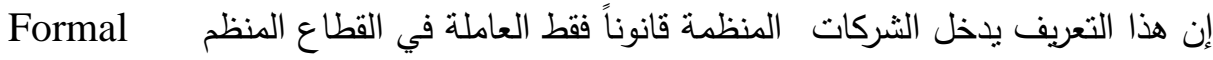
Sector

الجدول رقم ( 1) يورد قائمة بأسماء هذه الثركات التي تعمل في بناء الهياكل الخرسانية للمنشآت وهي إحدى وعشرون شركة.

تم تعميم إستمارة حصر بغرض جمع البيانات الإحصائية لهذه الشركات وهي تحتوبي على تهلى

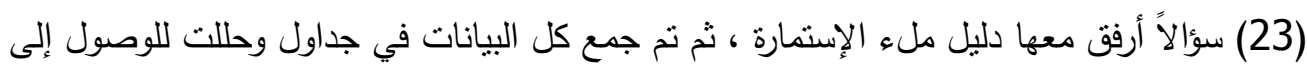
نتائج ومقارنتها بهدف قياس إنتاجية العامل السوداني في أعمال الخرسانة.

جدول رقم (1) الشركات العاملة في قطاع الإنشاءات الخرسانية في ولاية الخرطوم

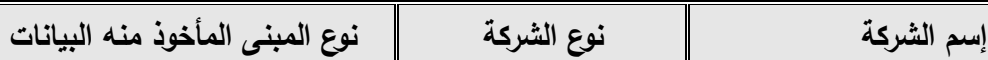


مجلة العلوم الهندسية - العدد الثالث- 2008

\begin{tabular}{|c|c|c|c|}
\hline منشآت عامة سكنية & عامة & النصر & 1 \\
\hline منشآت عامة & عامة & شواهق (ب) & 2 \\
\hline سكني & خاصة - & مماصم & 3 \\
\hline تجاري & خاصة - & عبد الله حسن الطاهر & 4 \\
\hline سكني خاص & خاصة & ريشكو & 5 \\
\hline سكني خاص & خاصة & فتح الرحمن الهندسية & 6 \\
\hline منشأة عامة & 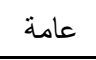 & دان فوديو & 7 \\
\hline منشأة عامة & 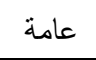 & شواهق (أ) & 8 \\
\hline منشأة عامة & خاصة & شركة إنجاز (ب) & 9 \\
\hline منشأة عامة & خاصة & شطاية & 10 \\
\hline منشأة عامة & خاصة & شركة إنجاز (أ) & 11 \\
\hline منشأة عامة & خاصة & شركة دي سي الهندسية & 12 \\
\hline منشأة عامة & خاصة & شركة فلاتكو العالمية & 13 \\
\hline منشأة عامة & خاصة & أعمال علي دنقلا & 14 \\
\hline سكني خاص & خاصة & بادية الهندسية & 15 \\
\hline إستثماري تجاري & عامة & شركة قصر اللؤلؤ & 16 \\
\hline سكني خاص & خاصة & شركة المشرف للتجارة والنشييد & 17 \\
\hline منشأة عامة & خاصة & شركة البنيان المحدودة & 18 \\
\hline سكني خاص & خاصة & شركة الفداء للمقاولات الهندسية & 19 \\
\hline إستثماري تجاري & خاصة & شركة رمسيس الهندسية & 20 \\
\hline سكني خاص & خاصة & شركة عز المدينة للمقاولات & 21 \\
\hline
\end{tabular}

المصدر : إتحاد المقاولين السوداني

الجدول (1) يبين الثركات العاملة في قطاع الإنشاءات الخرسانية في ولاية الخرطوم وهي

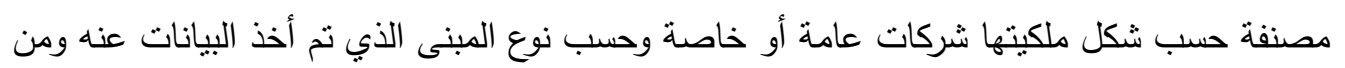
الجدول يتبين لنا أن هناك خمس شركات عامة وستة عثر شركة خاصة (الثركات العامة حصرت

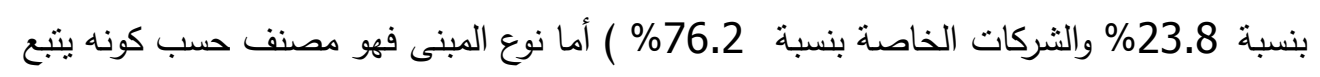
للقطاع العام أو الخاص والمبنى الخاص مصنف على حسب كونه مبنى سكني أو تجاري إستثماري. 
وعليه فإن المنشآت العامة تمثل نسبة 52.4\% والمنشآت التجارية الإستثمارية تمثل نسبة 47.6\%

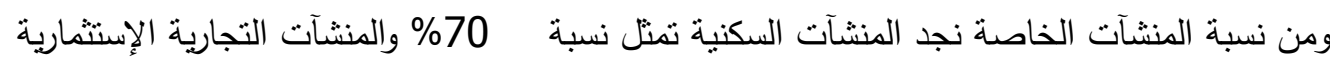
والخاصة تمنل نسبة 30\% من جملة المنشآت الخاصة.

ومن هنا يتضح أن سوق المنشآت العامة في مجال حيوي للتنافس بين الثركات العامة

والخاصة ، ويلاحظ أن هنالك شركة عامة واحدة فقط نولت العمل في منشأة تجارية إستثمارية خاصة

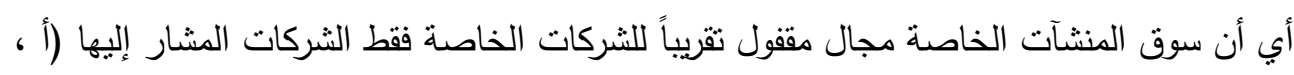
ب) رسى لها موقعين لشركتين من الباطن.

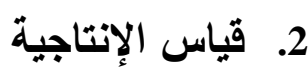

تتضمن أدبيات قياس الإنتاجية نوعين رئيسيين من مقاييس الإنتاجية هما: [4]

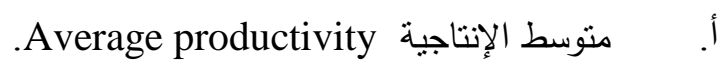

ب. ب. بالإنتاجية الحدية Marginal productivity.

يرتبط نوع الإنتاجية بنوع عامل الإنتاج الذي يراد قياس إنتاجيته ومنهجية قياس هذه الإنتاجية - ل

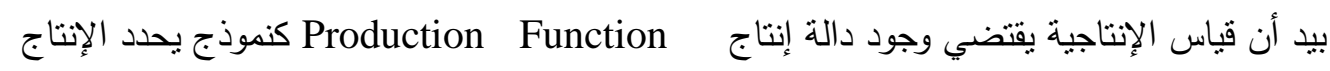
كتوليفة Combination لعوامل الإنتاج ، هذا سواء كانت هذه التوليفة خطية Linear أو غير دئ خطية non -linear

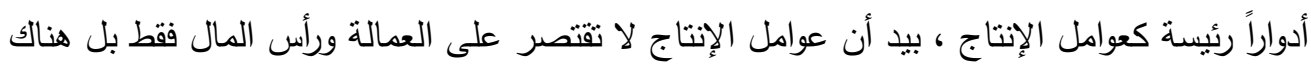
مدخلات إنتاج أخرى وسيطة تلعب دوراً مهماً في العملية الإنتاجية.

\section{3. قياس الإنتاجية في الثركات السودانية}

ركزنا هنا على قياس عاملي العمالة ورأس المال في دالة الإنتاج المعتمدة في هذه الدراسة

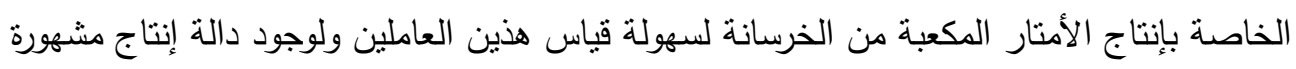

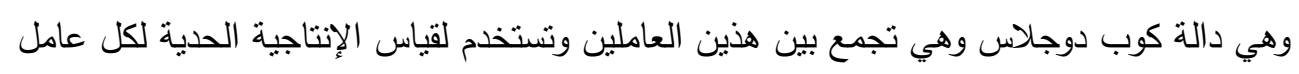


من عاملي الإنتاج في هذه الدالة وسوف يتم قياس منوسط إنتاجية العامل السوداني في الخرسانات ثم قياس الإنتاجية الحدية لكل من العمالة ورأس المال.

$P=f(L) \_$(Production is a function of Labour)

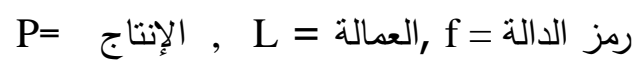

$\mathrm{P}=\mathrm{L}(\mathrm{APL})$

APL (Average Productivity of Labour)منوسط إنتاجيه العامل في كل الفترة

$(\mathrm{APL})=\frac{P}{L}$

$($ APLd $)=\frac{P}{L \times T}$ متوسط إنتاجية العامل في اليوم

(APLd)i $=\frac{P i}{L i \times T i} i$ الإنتاج في الشركة

بحساب المعادلة أعلاه لكل شركة نحصل على متوسط إنتاجية العامل لكل شركة من شركات

الدراسة جدول (2).

هناك فوارق كبيرة بين معدلات الإنتاجية للعامل الواحد في اليوم لهذه الثركات ، لا يعزي

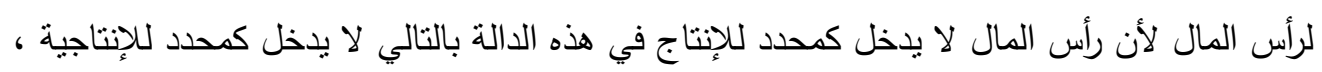

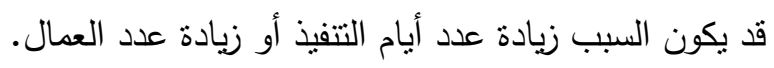

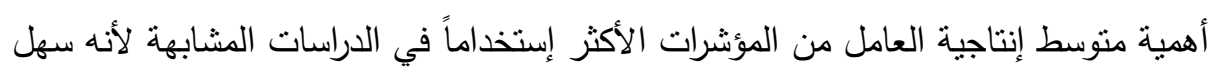

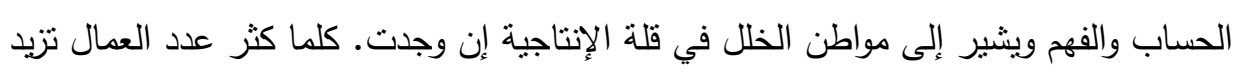

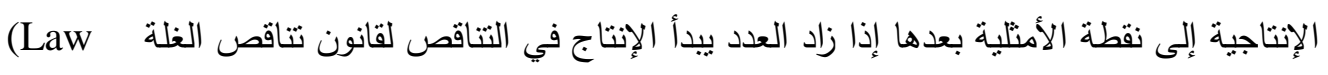
of diminishing returns) ويمكن حساب منوسط إنتاجية العامل لكل هذه الثركات حتى نخلص إلى مؤشر واحد يعطي منوسط إنتاجية العامل في قطاع الإنشاءات الخرسانية في الخرطوم وذلك بإستخدام المتوسط المرجح 
لمعدلات متوسط إنتاجية العامل في كل الثركات ويحسب المتوسط المرجح لمتوسط إنتاجية العامل

$\mathrm{WALP}=\frac{\sum f i(A L P D) i}{\sum f i}$

WALP $=($ Weighted Average Labour Productivity $)$

(WALP) = المنوسط المرجح لمتوسطات إنتاجية العامل

رأس المال المنسخدم في بناء الهياكل الخرسانية (التقانة - قيمة المعدات) = fi / في الثركة

وهنا يدخل رأس المال كعنصر ترجيح Weighting Factor) لأن الإنتاج بصورة عامة

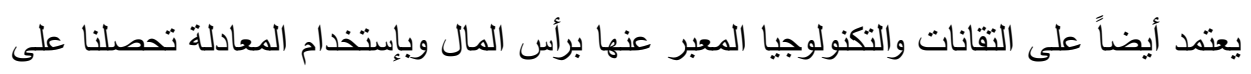
المتوسط المرجح لمتوسطات إنتاجية العامل في شركات الإنشاءات الخرسانية وهو 0.45 م3 / اليوم.

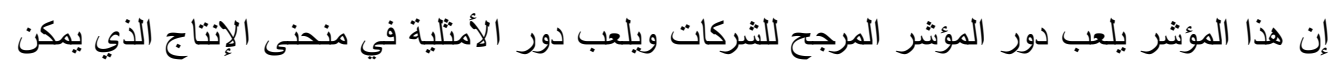
رسمه من هذه المعادلة وهو المتوسط الأدنى الذي يجب لعزئ على العامل إنتاجه في اليوم.

جدول رقم (2) متوسط إنتاجية العامل في شركات الإنشاءات الخرسانية في ولاية الخرطوم

\begin{tabular}{|c|c|c|c|c|}
\hline 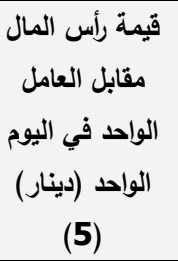 & 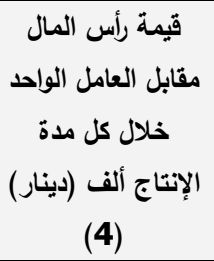 & في اليوم (م3 خرسط إنتاجية العاملة) & إسم الثركة (2) & $\begin{array}{c}r \\
(\mathbf{1})\end{array}$ \\
\hline 4.165 & 195.745 & 0.76 & النصر & 1 \\
\hline 21.111 & 633.333 & 0.48 & شواهق (ب) & 2 \\
\hline 25.000 & 500.000 & 0.76 & مماصم & 3 \\
\hline 3.917 & 117500 & 0.39 & عبد الله حسن الطاهر & 4 \\
\hline 12.353 & 420.000 & 0.26 & ريشكو & 5 \\
\hline 3.667 & 110.000 & 0.37 & فتح الرحمن الهندسية & 6 \\
\hline
\end{tabular}


مجلة العلوم الهندسية - العدد الثالث- 2008

\begin{tabular}{|c|c|c|c|c|}
\hline 20.370 & 550.000 & 1.65 & دان فوديو & 7 \\
\hline 24.575 & 565.217 & 0.28 & شواهق (أ) & 8 \\
\hline 1.932 & 133.333 & 0.11 & شركة إنجاز (ب) & 9 \\
\hline 17.751 & 461.1538 & 0.24 & شطاية & 10 \\
\hline 66.667 & 1.000 .000 & 0.24 & شركة إنجاز (أ) & 11 \\
\hline 14.403 & 388.889 & 0.41 & شركة د.سي (D.C) الهندسية & 12 \\
\hline 4.861 & 291.667 & 0.92 & فلاتكو العالمية & 13 \\
\hline 1.250 & 75.000 & 0.33 & أعمال علي دنقلا & 14 \\
\hline 3.469 & 128.378 & 0.16 & بادية الهندسية & 15 \\
\hline 27.778 & 166.667 & 1.29 & شركة قصر اللؤلؤ & 16 \\
\hline 4.756 & 137.931 & 0.29 & حسن المشرف للتجارة والتشييد & 17 \\
\hline 9.512 & 827.587 & 0.49 & شركة البنيان المحدودة & 18 \\
\hline 19.568 & 103.713 & 0.23 & شركة النداء المحدودة & 19 \\
\hline 4.524 & 67.867 & 0.15 & شركة رمسبس الهندسية & 20 \\
\hline 92.593 & 333.333 & 0.31 & شركة عز المدينة للمقاولات & 21 \\
\hline
\end{tabular}

المصدر : دراسة ميدانية قام بها الباحث

يظهر في الجدول (2) فقط خمس شركات فوق المتوسط.

(3) الجدول يوضح متوسط إنتاجية كل شركة على حده في العمود (3).

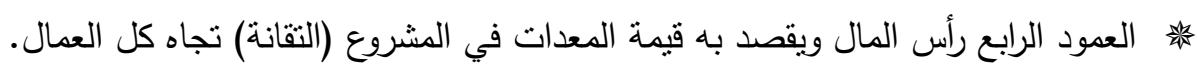

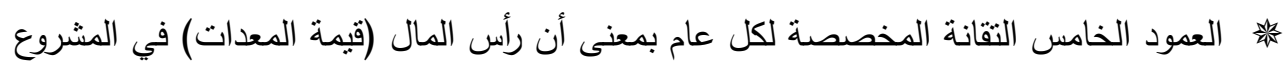

قسمت على عدد العمال في المشروع (النقانة التي يستخدمها العمال).

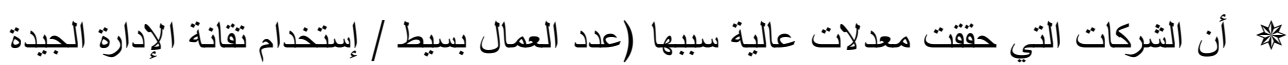
للمشروع).

قارنا إنتاجية العامل في السودان مع إنتاجية العمال في دول العالم - الجدول رقم (3). 


\section{جدول رقم (3) إنتاجية العامل في السودان ويعض الدول}

\begin{tabular}{|c|c|c|c|c|}
\hline ملحوظات & معدل الإنتاجية & وحدة قياس الإنتاجية & السنة & الدولة الدئ \\
\hline معدل الإنتاجية متوسط مرجح لمتوسطات & 0.45 & ماحد / موم عمل لعامل & 2003 & السودان \\
\hline شركة Farnborough شركة Birmingham الإنجليزية & $\begin{array}{r}7.8 \\
10.9\end{array}$ & م ماعات عمل & 1999 & $\begin{array}{r}\text { بريطانيا } \\
\text { (6) }\end{array}$ \\
\hline شركة Cannes شركة الفرنسية & $\begin{array}{r}5.8 \\
10.6\end{array}$ & م ماعات عمل & 1999 & $\begin{array}{r}\text { فرنسا } \\
\text { (6) }\end{array}$ \\
\hline 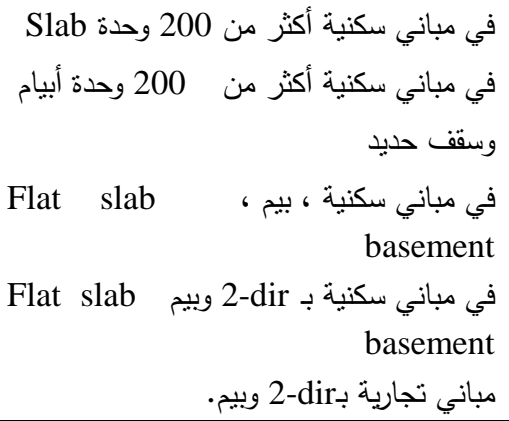 & $\begin{array}{l}0.99 \\
1.05 \\
0.25 \\
0.17 \\
0.37 \\
0.33\end{array}$ & م 2 / ساعات عمل & 1992 & سنغافورة \\
\hline & 1.5 & ماحد / ميوم عمل لعامل & 1994 & مصر \\
\hline & $\begin{array}{l}0.40 \\
0.45\end{array}$ & م / ساعة عمل & 1990 & $\begin{array}{r}\text { السويد } \\
\text { (8) }\end{array}$ \\
\hline
\end{tabular}

المصادر : حسب الأرقام الموضحة قرين كل بلد.

يلاحظ في هذا الجدول (3) تدني إنتاجية العامل السوداني مقارنة بكل من العامل في فرنسا وبريطانيا وسنغافورة ومصر ، ويعزى أسباب تدني الإنتاجية في السودان إلى مؤشرات عديدة منها: • بدائية التقانة المستخدمة في النتييد وحداثة دخول الثقانة المنقدمة.

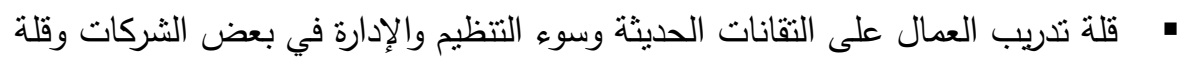
الإثراف على المشاريع والتحفيز ويضاف إلى ذلك أن الظروف المناخية وحرارة الطقس في ولثي

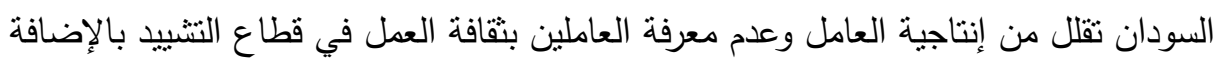

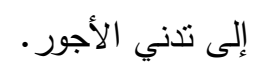




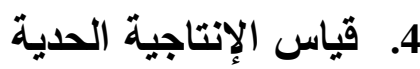

يتم حساب معدل الإنتاجية الحدية للعامل الواحد بمنطق أجره من دالة إنتاج كوب دوجلاس بأخذ المشتقة الأولى للإنتاج على عنصر العمالة حيث أن المتغيرات والمعلمات كما هي موضحة الإنة أعلاه فإن المشتقة الأولى (P) على (L) هي الإنتاج مقسوم على العمالة.

بإستخدام دالة كوب دوجلاس (3):

$\mathrm{P}=A \stackrel{\alpha}{K} \stackrel{\beta}{L}$

$$
\text { الإنتاجث أن }
$$

A يراد تقدير ها Parameter

$$
\text { K رأس المال = }
$$

L العمالة

$\alpha, \beta$ معالم براد تقديرها

المعادلة يمكن أن تصاغ في علاقة خطية في القيم اللوغرثمية لكل من الإنتاج ورأس المال:

$\mathrm{LnP}=\mathrm{LnA}+\alpha \operatorname{LnK}+\beta \mathrm{LnL}$

حيث أن Ln = اللوغاريثم الطبيعي وعليه فأن تقديرات الأسس يجب أن تمثل مساهمة كل من رأس Marginal rate of Labor المال والعمالة في الإنتاج ، معدل الإنتاجية الحدية للعمالة

$$
\begin{aligned}
\frac{\partial P}{\partial L}= & \beta A \stackrel{\alpha \beta}{K} \stackrel{\beta}{L} \\
& =\frac{\beta}{L} A K L \\
& =\frac{\beta P}{L}
\end{aligned}
$$

Productivity (MRLP)

معدل الأجور يساوي معدل الإنتاجية. W 
MRLP =W

$W=\beta \frac{(P)}{L}$

$$
\text { ( مساهمة العمالة في الإنتاج) } \quad \beta=\frac{W L}{P}
$$

لأن (WL) هو جملة الأجور و هو الإنتاج ، فإن الإنتاج.

معدل الإنتاجية الحدية للعمالة بمنطوق الأجور ، أي أن هذا المعدل يعطي تكلفة إنتاج المتر المكعب الواحد في اليوم بحساب أجر العامل في اليوم.

\section{5. تقدير الالأة وإختبار الفروض}

إن تقدير معادلة كوب دوجلاس الخطية يتبعه إختبار للفروض ، تعطي معلومات عن مدى

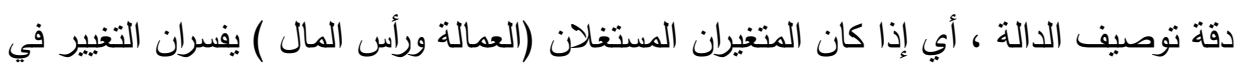
الإنتاج وعليه فإن الفروض هي:

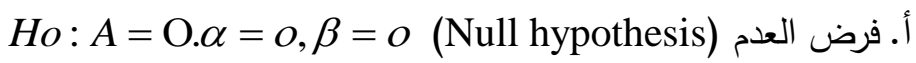

$$
\begin{aligned}
& \text { بi: } A \neq 0, \alpha \neq 0, \beta \neq 0 \text { (Alternative) ب الفرض البديل }
\end{aligned}
$$

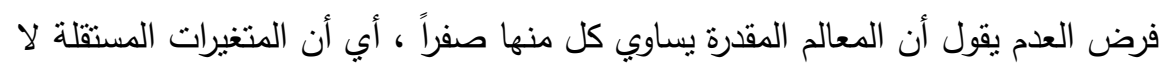

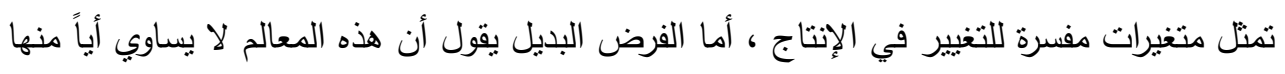
الصفر وعند تقدير المعادلة نم الحصول على النتائج التالية:

$\mathrm{LnQ}=0.971+1.064 \mathrm{~L} \mathrm{~nL}+\mathrm{L} \mathrm{n} \mathrm{K}$

(0.980) (4.081) (3.301)

$$
\mathrm{F}=15.925 R^{2}=63.9 \%
$$


قيم الإحصاءة (t) بين القوسين من واقع بيانات الجدول (8) عند إدخالها للحاسوب ومعالجتها بالبرنامج (spss)

$$
\text { ثم حدود الثقة للمعالم }
$$

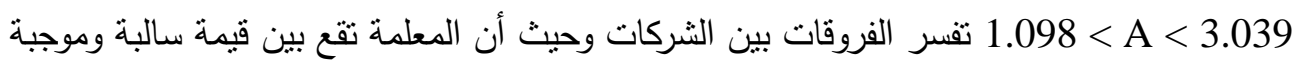

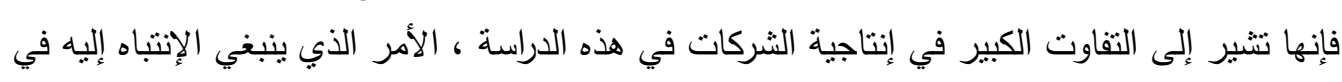
عملية الإنتاج في كل قطاع. 0.516 $0.5 \prec 1.611$ $0.206 \prec \alpha \prec 0.928$

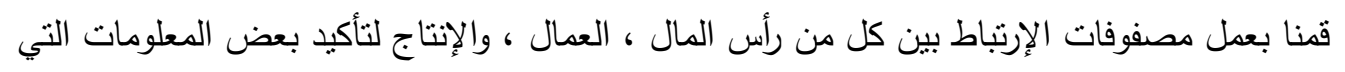
توصلنا إليها.

جدول رقم (4) مصفوفة الإرتباط رقم (1)

\begin{tabular}{|c|c|c|c|}
\hline الإنتاج & العمالة & رأس المال & الإرتباط \\
\hline 0.55 & 0.137 & 1 & رأس المال \\
\hline 0.648 & 1 & 0.137 & العمالة \\
\hline 1 & 0.656 & 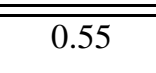 & الإنتاج \\
\hline
\end{tabular}

إن هذا الإرتباط بين العمالة ورأس المال ليس معنوياً عذد درجة الثقة ( 95\%) مما بعني قلة المعرفة التقنية للعمال (Technical know - how) وهي المعرفة المطلوبة لنتخغيل هذه المعدات بكفاءة في الزمان والمكان.

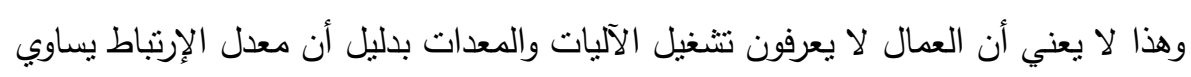

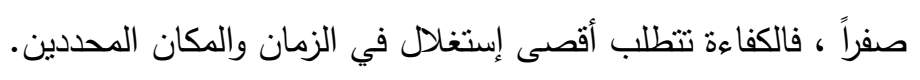

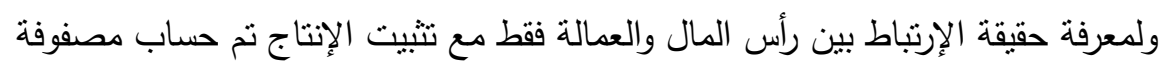

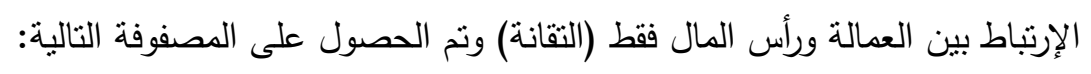


جدول رقم (5) مصفوفة الإرتباط رقم (2) بين رأس المال والعمالة

\begin{tabular}{|c|c|c|}
\hline رأس المال & العمالة & \\
\hline 0.137 - & 1 & العمالة \\
\hline 1 & 0.137- & رأس المال \\
\hline
\end{tabular}

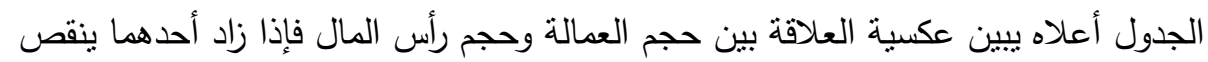

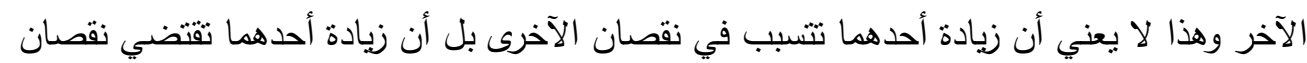
الآخر فالنقطة المنلى للتوازن هي نقطة الأمثلية التي يكون فيها الإرتباط بين المتغيرين موجباً ومعنوياً ،

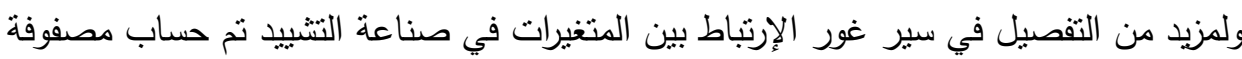
الإرتباط التالية:

جدول رقم (6) مصفوفة الإرتباط رقم (3) بين رأس المال والعمال المهرة والعمال الغير مهرة والأجور

\begin{tabular}{|c|c|c|c|c|}
\hline الأجور & العمال غير المهرة & العمال المهرة & رأس المال & \\
\hline-0.239 & -0.237 & 0.086 & 1 & رأس المال \\
\hline-0.374 & -0.2459 & 1 & 0.086 & العمال الدهرة \\
\hline-0.421 & 1 & -0.259 & -0.237 & العمال غير المهرة \\
\hline 1 & -0.421 & -0.374 & -0.239 & الأجور \\
\hline
\end{tabular}

نم تماب مصفوفة الإرتباط ( 3) فالجدول (7) بناء علي البيانات الواردة حسب البنود الموضحة

$$
\text { في الجدول. }
$$

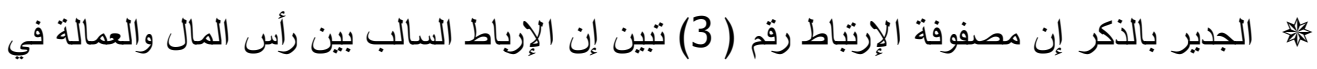

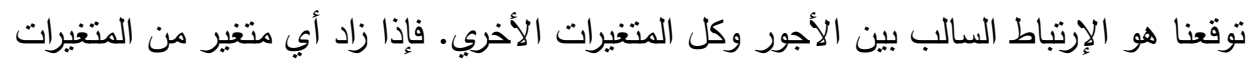

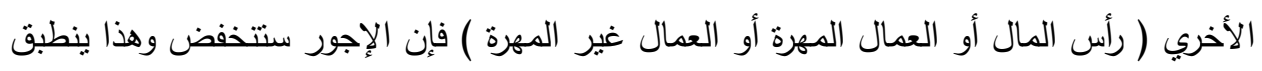

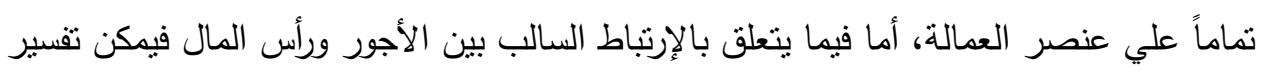
ذلك بإن زيادة رأس المال تؤدي إلي إستخدام أقل للعمال ( يقل الطلب علي العمال بوجود التقانة ) مما يؤدي ذللك إلي إن يعرض العامل خبرته وقوته بسعر أقل في سوق العمل حتي يتحصل علي إني

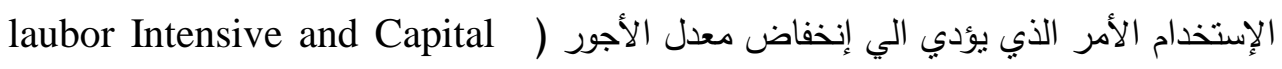

.(Intensive 
هذه النتائج تدعو إلي رسم سياسة إقتصادية الهذف منها ديناميكية هذا القطاع بسبب نسهيل شروط نموه ليسهم في دفع مسار الإقتصاد القومي ويمكن تطبيق المعادلة ( 10) لحساب الخسائر والفوائد

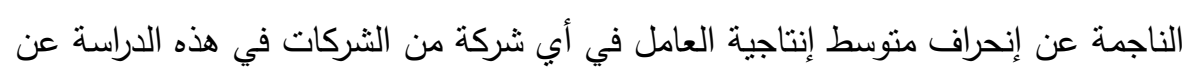
المتوسط المرجح لمتوسطات إنتاجية العامل.

$(A L P) I=\frac{P i}{L i \times t i}$
$L i=\frac{P i}{(A L P) I \times T i}$

هذا النموذج يمكن أي شركة من الثركات لإستخدامه لتحديد عدد العمال للمشروع أو تحديد الزمن ويعتبر نموذج محوري. جدول رقم (7) الفوائد (-) أو الخسائر (+) الناجمة عن إنحراف متوسط إنتاجية العامل عن المتوسط

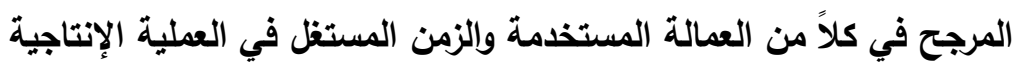

\begin{tabular}{|c|c|c|c|c|c|c|c|c|c|}
\hline المهرد الموفر & $\mathbf{T i}$ & & الختو التوفير & li-li & $\mathbf{L i}$ & $\mathbf{L i}$ & اللإنتاجية المرجح & إلتتاجية & إسم الثركة \\
\hline $28^{-}$ & 98 & 70 & $862^{-}$ & $19-$ & 66 & 47 & 0.54 & 0.76 & 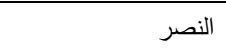 \\
\hline $5+$ & 35 & 40 & $0.265^{+}$ & $4+$ & 26 & 30 & 0.54 & 0.48 & شواهق (ب) \\
\hline $8^{-}$ & 30 & 22 & $0.246^{-}$ & $8^{-}$ & 28 & 20 & 0.54 & 0.75 & مماصم \\
\hline $6+$ & 14 & 20 & $0.288^{-}$ & $9+$ & 21 & 30 & 0.54 & 0.39 & عبد الله حسن الطاهر \\
\hline $26+$ & 22 & 48 & $1.08+$ & $18^{+}$ & 16 & 34 & 0.54 & 0.25 & رشكو \\
\hline $8^{+}$ & 17 & 25 & $0.350+$ & $10+$ & 20 & 30 & 0.54 & 0.36 & فتح الرحمن الهندسية \\
\hline $28-$ & 42 & 14 & $1.466^{-}$ & $18-$ & 107 & 26 & 0.54 & 1.64 & دانفوديو \\
\hline $15^{+}$ & 15 & 30 & $0.504+$ & $12+$ & 11 & 23 & 0.54 & 0.27 & شواهق (أ) \\
\hline $22+$ & 16 & 38 & $0.495^{+}$ & $9+$ & 6 & 15 & 0.54 & 0.24 & شركة إنجاز (ب) \\
\hline $7+$ & 23 & 30 & $0.420+$ & $7+$ & 20 & 27 & 0.54 & 0.41 & شركة دي سي الهندسية \\
\hline $6-$ & 26 & 20 & $0.240^{-}$ & $16^{-}$ & 76 & 60 & 0.54 & 0.68 & فلاتكو العالمية الهندسية \\
\hline $6^{+}$ & 9 & 15 & $0.41+$ & $23+$ & 37 & 60 & 0.54 & 0.33 & أعمال علي دنقلا \\
\hline
\end{tabular}


د. إبراهيم محمد أحمد

المؤشر الإنتاجي لأعمال الخرسانات المصبوبة بالمكان في السودان

\begin{tabular}{|c|c|c|c|c|c|c|c|c|c|}
\hline $21+$ & 9 & 30 & $0.585^{+}$ & $26^{+}$ & 11 & 37 & 0.54 & 0.16 & بادية الهندسية \\
\hline $41-$ & 71 & 30 & $3.735^{-}$ & $83^{-}$ & 143 & 60 & 0.54 & 0.29 & شركة قصر اللؤلؤ \\
\hline $15+$ & 15 & 30 & $0.762+$ & $14+$ & 15 & 29 & 0.54 & 0.28 & شركة المشرف للتجارة والتنشييد \\
\hline $14+$ & 106 & 120 & $1.560+$ & $15^{+}$ & 77 & 87 & 0.54 & 0.48 & شركة البنيان المحدودة \\
\hline $16^{+}$ & 8 & 20 & $0.620+$ & $31+$ & 22 & 53 & 0.54 & 0.23 & شركة النداء للمقاولات \\
\hline $44+$ & 16 & 60 & $9.81+$ & $109+$ & 41 & 150 & 0.54 & 0.15 & شركة رمسيس الهندسية \\
\hline $7+$ & 8 & 15 & $0.360+$ & 16 & 20 & 36 & 0.54 & 0.31 & شركة عز المدينة \\
\hline
\end{tabular}

المصدر : دراسة الباحث

هذا الجدول (7) يبين الخسارة أو الأرباح الناتجة من المشروع الذي أخذت منه البيانات لكل

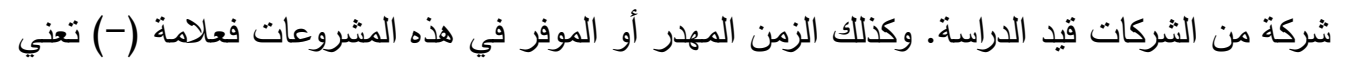
هناك أرباح محققة أو زمن موفر وعلامة (+) تعني إن هناك خسارة في العملية الإنتاجية أو هناك زمن فئن مهدر • ويلاحظ من الجدول إنه إذا أخذنا إنحراف معدل إنتاجية العامل كأساس عن المعدل المناج المرجح

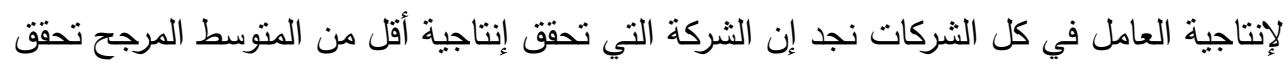

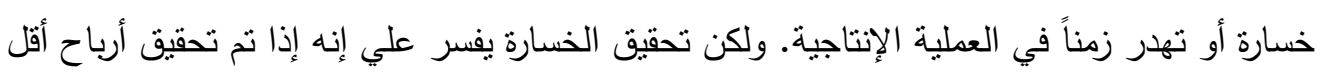
مما يقتضيه حجم العمل فإن ذلك خسارة أو إن هذه الخسارة هي في الحقيقة ربح ضائع أو مهرد .

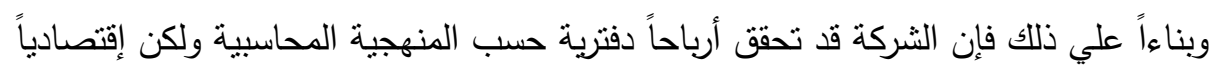

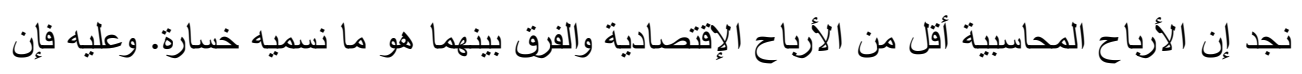

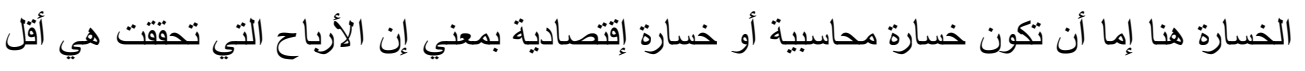
مما ينبغي أو مما يقتضيه حجم العمل. فالربح الإقتصادي أعلي من الربح المحاسبي ويمكن تفسير الربح الإقتصادي بإنه مؤشر لكفاءة التشغيل وكفاءة الإدارة ( Efficiency ).

جدول رقم (8) الإنتاج وعوامل الإنتاج في الثركات 
مجلة العلوم الهندسية - العدد الثالث- 2008

\begin{tabular}{|c|c|c|c|c|c|c|c|}
\hline 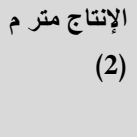 & مليون دينار & 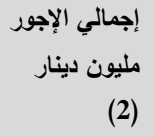 & إلعمالي & (2) عمال مهزة & غمال & إسم الشركة (2) & (1) \\
\hline 2512.00 & 9.20 & 4.61 & 47.00 & 7.00 & 40.00 & النصر & 1 \\
\hline 576.00 & 19.00 & 1.92 & 30.00 & 4.00 & 26.00 & شواهق (ب) & 2 \\
\hline 333.00 & 10.00 & .66 & 20.00 & 4.00 & 16.00 & مماصم & 3 \\
\hline 236.40 & 4.70 & .96 & 30.00 & 7.00 & 23.00 & عبد اله حسن الطاهر & 4 \\
\hline 418.00 & 14.30 & 2.45 & 34.00 & 8.00 & 26.00 & رشكو & 5 \\
\hline 276.00 & 3.30 & 1.05 & 30.00 & 3.00 & 27.00 & فتح الرحمن الهندسية & 6 \\
\hline 600.00 & 14.30 & .53 & 26.00 & 6.00 & 20.00 & دان فوديو & 7 \\
\hline 191.00 & 13.00 & .97 & 23.00 & 6.00 & 17.00 & شواهق (أ) & 8 \\
\hline 300.00 & 9.20 & 4.42 & 69.00 & 6.00 & 36.00 & شركة إنجاز (ب) & 9 \\
\hline 184.00 & 12.00 & 1.09 & 26.00 & 9.00 & 17.00 & شطايا & 10 \\
\hline 137.00 & 15.00 & .83 & 15.00 & 4.00 & 11.00 & شركة إنجاز (أ) & 11 \\
\hline 136.00 & 10.50 & 1.62 & 26.00 & 6.00 & 20.00 & شركة دي سي الهندسية & 12 \\
\hline 826.00 & 17.50 & .90 & 60.00 & 15.00 & 45.00 & فلاتكو الهندسية العالمية & 13 \\
\hline 450.00 & 40.50 & 1.07 & 60.00 & 20.00 & 40.00 & أعمال علي دنقلا & 14 \\
\hline 182.00 & 4.75 & .83 & 27.00 & 9.00 & 28.00 & بادية الهندسية & 15 \\
\hline 2330.00 & 10.00 & 2.70 & 60.00 & 20.00 & 40.00 & شركة قصر الؤلؤ & 16 \\
\hline 250.00 & 4.00 & 1.39 & 29.00 & 7.00 & 22.00 & حسن المشرف للتجارة والتشييد & 17 \\
\hline 5000.00 & 72.00 & 13.57 & 87.00 & 22.00 & 65.00 & شركة البنيان المحدودة & 18 \\
\hline 226.00 & 5.50 & 1.06 & 53.00 & 10.00 & 43.00 & شركة النداء للمقاولات & 19 \\
\hline 1350.00 & 10.18 & 13.50 & 80.00 & 20.00 & 60.00 & شركة رمسيس الهندسية & 20 \\
\hline 170.00 & 12.00 & 0.81 & 36.00 & 6.00 & 30.00 & شركة عز المدينة للمقاولات & 21 \\
\hline
\end{tabular}

المصدر در اسة الباحث

\section{6. أهم النتائج من دراسة دالة كوب دوقلاس وعلاقات الإرتباط بين المتغيرات}

أ. إن العمال ورأس المال متغيران مفسران للتغير في دالة إنتاج الإنشاءات الخرسانية المصبوبة

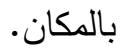


ب. إن العمال ورأس المال يفسران 63.9\% من التغير في الإنتاج مما يعني إن هناك عوامل أخري تؤثز في الإنتاج مما ينبغي البحث عنها وتحديدها وقياس نأثثر كل منها في الإنتاج كالإدارة مثنالً.

ج. هنالك إرتباط موجب بين كل من الإنتاج ورأس المال والعمالة كما هو منوقع في العملية الإنتاجية (أهمية المحافظة على العدد المناسب لتتفيذ العمل).

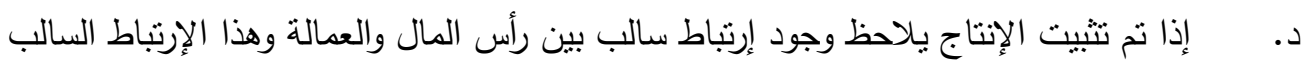
مرده إلي حجم العمالة غير الماهرة (أهمية تدريب العمال لتحسين الإنتاجية).

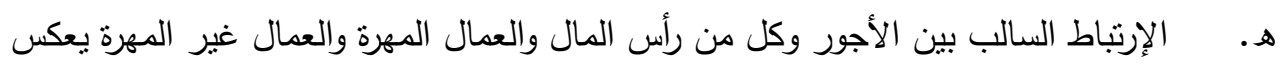

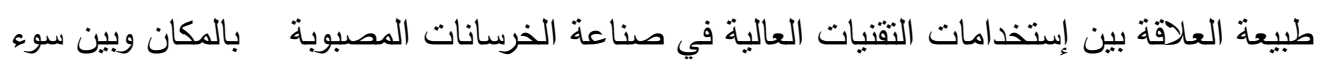
الإستخدام Employment في سوق الإنشاءات الخرسانبة المصبوبة أهمية تدريب العمال على فئل (التقانات).

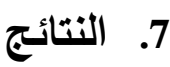
أ.الهدف تطوير تقنيات أساليب تتفيذ الهياكل الخرسانية. ب. الإنتاجية عنصر من العناصر الهامة لإقتصاديات التشييد هدفنا لمعرفة إنتاجية شركات التشييد السودانية في أعمال تتفيذ الهياكل. ج. وصلنا لإسباب تدني الإنتاجية والتي تقود لإصلاحها أو رفعها، منها :-

$$
\begin{aligned}
& \text { 1 } \\
& \text { 2. 2 العمالة غيرالمدربة. } \\
& \text { 3. الإدارة غير الجيدة للمشروعات والثركات. } \\
& \text { 4. أخطاء التصميم وعدم وجود التتسيق مع المنفذين. } \\
& \text { 5. } \\
& \text { 6. كثرة العمال في المشروع مقارنة مع حجم الإنتاج في المشروع. }
\end{aligned}
$$

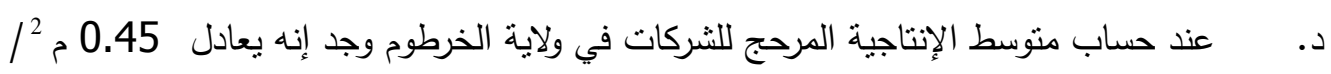

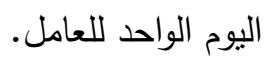




$$
\begin{aligned}
& \text { هـ . تقع أهمية هذا المتوسط في إنه يساعد علي معرفة عدد العمال المراد تنغيلهم في المشروع }
\end{aligned}
$$

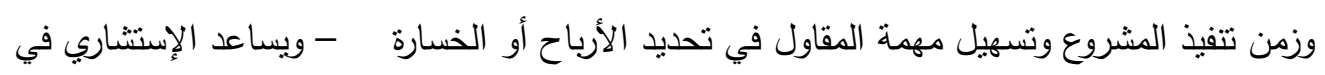

$$
\begin{aligned}
& \text { تحديد إمكانية الثركة المختارة في تتفيذ المشروع في المدة المحدة بواسطة صاحب العبد العمل. }
\end{aligned}
$$

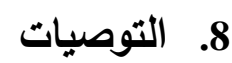

على وزارة الثئون الهندسية والتتمية العمرانية وإتحاد المهندسين والجمعية الهندسية إتحاد المقاولين وضع إستراتيجية قصيرة المدي ومتوسطة المدي لرفع الكفاءة الإنتاجية داخل قطاع التشييد لزيادة مساهمة القطاع في إجمالي الناتح المحلي وذلك بتعديل قيمة المتوسط المرجح من وقت لآخر

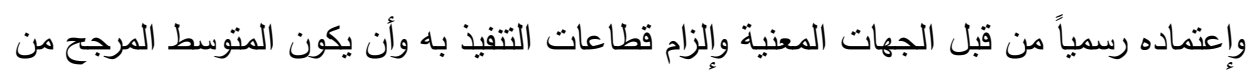
الأسس التي يتم إختبار الشركات علي أساسه لنتفيذ عقودات الدولة.

1. د. محمد هاشم عوض - توزيع الثروة في السودان - دراسة عن الإبداعات المصرفية - مقدمه

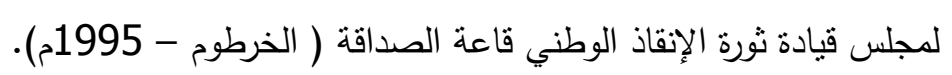

2. عبد اللطيف أبو العطاء البقري - الموسوعة الهندية لإنثاء المباني والمرافق العامة المجلد الأول

$$
\text { والثاني الطبعة الخامسة 1994م مكتبة الأنجلو المصري } 165 \text { شارع محمد فريد. }
$$

3. Aspen Urban - Productivity Development in Swedish Industry and Commerce, Trycher publishers, Stockholm 1991.

4. Lowe J.G the Measurement of Productivity in the Construction Industry Construction Management \& Economics, No, 51987, PP 103-113.

5. Stephenal. G. Construction Economic an Introduction - Printed in Great Britain by Rowe Ltd. 1997.

6. Survey in the Malaysian Industry, Construction Management and Economics 19.8.2001.

7. Suipheng Quantifying the Relationship between Build Ability, Structural Quality and Productivity in Construction, Standard Survey, Volume 19 P 106-112. Nov 2001.

8. Thomas - H.K. Zaurshi Lvical Construction Base Line Productivity Theory and Practice 2001. 